\title{
ACOLHIMENTO INSTITUCIONAL: O relato de experiência de estágio em uma casa de acolhimento de crianças
}

DOI: 10.22289/2446-922X.V4N3A4

\author{
Adarlene Gonçalves Fonseca Alves ${ }^{1}$ \\ Karla Priscilla Lemgruber
}

\section{RESUMO}

O presente relato de experiência tem como objetivo apresentar o aprendizado obtido durante o Estágio Básico II do $7^{\circ}$ período do curso de Psicologia da Faculdade de Patos de Minas, capacitando e auxiliando o graduando a lidar com a realidade em uma casa de acolhimento institucional para crianças e adolescentes. Foram realizadas observações, entrevistas técnicas e momentos de supervisão que nortearam as atividades realizadas no estágio. Este estudo faz parte da produção resultante do Projeto de Pesquisa Relatos de Casos \& Relatos de Experiência: a prática desenvolvida no CEPPACE do DPGPSI/FPM. Submetido à apreciação ética do Comitê de Ética e Pesquisa (CEP) com Seres Humanos da Faculdade Patos de Minas, CAEE: 92972318.0.0000.8078, tendo como instituição proponente a Associação Educacional de Patos de Minas - AEPM mantenedora da Faculdade Patos de Minas, sob parecer de aprovação número: 2.758.999, de 06 de julho de 2018. Foi percebido que as crianças necessitavam de um momento lúdico que proporcionasse prazer e que também promovesse maior interação social entre elas. Diante de tal percepção foram executadas ações que poderiam auxiliar as crianças a conviver de forma mais harmoniosa no seu dia a dia enquanto institucionalizados. Acredita-se que o presente relato de experiência possa ser útil para psicólogos em formação e para demais interessados na técnica do brincar enquanto atividade promotora de sociabilidade.

Palavras-chave: Formação do psicólogo; Brincar; Interação infantil.

\section{ABSTRACT}

The main purpose of this work is to share the knowledge acquired during the Basic Internship II of the 7th period of Psychology course in the Faculdade Patos de Minas, elucidating its stages, enabling and assisting the Psychology student to deal with the reality in a children's and teenager shelter. Observations, technical interviews and moments of supervision guided the activities in the internship. This work is part of the production resulting from the research project Relatos de Casos \& Relatos de Experiência: a prática desenvolvida no CEPPACE do DPGPSI/FPM. Submission of the Comitê de Ética e Pesquisa (CEP) com Seres Humanos da Faculdade Patos de Minas, CAEE: 92972318.0.0000.8078, with the Associação Educacional de Patos de Minas AEPM as sponsor of the Faculdade Patos de Minas, of approval number: 2.758 .999 , dated July 6 , 2018. It was noticed that children needed a playful moment that provided pleasure and

\footnotetext{
1 Endereço eletrônico de contato: crpclaudinha@hotmail.com

Recebido em 21/08/2018. Aprovado pelo Conselho Editorial e aceito para publicação em 20/10/2018.
}

Rev. Psicol Saúde e Debate. Dez., 2018:4(3):32-45. 
promoted greater social interaction between them. Consider it all, actions were accomplished to help the children to live in a more harmonious place. It's believed that the present experience report may be useful for training psychologists and for other people interested in the technique of playing as a sociability promoting activity.

Keywords: Psychologist formation; Play; Child interaction.

\section{INTRODUÇÃO}

O Estágio Básico II do Curso de Psicologia foi realizado no primeiro semestre de 2017. Tratou-se de uma experiência prática realizada em grupo que contou com uma equipe de 6 (seis) estudantes de Psicologia e uma professora-supervisora. Dessa forma, o presente relato trata-se de uma reflexão posterior retratando as suas perspectivas e considerações.

As primeiras orientações e informações sobre como proceder nos primeiros contatos com a instituição foram fundamentais. Foi notado bastante ansiedade entre os estagiários, pois seria um trabalho de observação com montagem e execução de um projeto, mas ainda não existia o conhecimento necessário de como esse projeto seria executado.

As supervisões iniciais foram essenciais para as orientações de como proceder nos primeiros contatos com a instituição na qual seria realizado o estágio. Foram repassadas informações sobre a documentação a ser entregue na casa de acolhimento, entre elas: informar que seriam agendadas 6 (seis) visitas, com duração de 2 (duas) horas cada, postura em relação à instituição, aos funcionários e as crianças institucionalizadas. Estas instruções foram o alicerce para começar a desenvolver e executar o projeto.

O Estágio Básico II foi uma oportunidade de conhecer uma instituição e nela poder vislumbrar e acompanhar de perto a função do psicólogo e quais outras possibilidades de atuação dentro da mesma. Permitindo estar em diferentes contextos sociais, juntamente com outros profissionais, observando de modo sistemático a atuação do psicólogo dentro da casa abrigo.

O estágio supervisionado desenvolvido ao longo do curso deve preparar o aluno para desenvolver papéis específicos da sua formação. Os estagiários são diretamente orientados por membros do corpo docente da instituição formadora, que procuram assegurar a consolidação e articulação das competências estabelecidas, preparando os alunos para práticas profissionais de complexidade e responsabilidade progressivas com atuação voltada para pessoas, grupos, instituições e situações sociais (Brasil, 2004).

A prática se sucedeu em uma instituição de acolhimento de crianças e adolescentes que foram afastados de sua família de origem por ordem judicial e que aguardam a definição de sua

Rev. Psicol Saúde e Debate. Dez., 2018:4(3):32-45. 
custódia. Seu funcionamento é coordenado por uma equipe multidisciplinar composta por uma psicóloga, uma assistente social, cuidadores, entre outros.

De acordo com a Lei 12.010 de 2009 (Brasil, 2009), o acolhimento institucional é medida provisória e excepcional, utilizável como forma de transição para reintegração familiar ou, não sendo esta possível, para colocação em família substituta, não implicando privação de liberdade.

O acolhimento é feito através de medida judicial, após outros órgãos já terem realizado o acompanhamento para identificar se é realmente necessária a retirada da criança de seu núcleo familiar. O Estatuto da Criança e do Adolescente (ECA) estabeleceu a criação de casas abrigo (Lei 7.644, de 18/12/1987), para acolher crianças vítimas de todo tipo de agressão, constituído em 13 de julho de 1990, o ECA estabelece medidas sociais e protetivas que devem ser utilizadas para garantir os direitos de crianças e adolescentes (Brasil, 1990).

A equipe multidisciplinar monta um plano de ação (PIA) diferenciado para cada família atendida, de forma a atender as demandas específicas e auxiliá-las, o que exige uma intervenção transdisciplinar segura e integrada à realidade sociocultural de seus participantes. No Artigo 92 do ECA (Brasil, 1990), consta que o dirigente do abrigo atua como guardião das crianças, sendo responsável por elas no período em que se encontram institucionalizadas.

Esta equipe realiza funções técnicas relacionadas à área da infância e juventude como reintegrar a criança ao meio escolar, ajuda na socialização destes, cuidado da parte burocrática, e elaboração de documentos de entrada e saídas de crianças na instituição. O Psicólogo deve estar inserido em uma equipe, que se ocupa de diferentes tarefas, contribuindo com as necessidades do cotidiano das crianças institucionalizadas, de forma a proporcionar um ambiente tranquilo e acolhedor, minimizando as marcas da violência trazidas pela sua história de vida (Antoni \& Koller, 2001).

As atividades grupais com as crianças devem ser de enfoque socioeducativo, a fim de trabalhar aspectos referentes à integração, cooperação, autoestima e adoção, ou seja, todas as questões que permeiam a vivência institucionalizada. De acordo com a literatura pesquisada, não há um modo de atuação específico do psicólogo em abrigo. Podem ser realizados tanto atendimentos grupais quanto clínicos ou institucionais (Hoepfner, 2004; Rotondaro, 2002).

As cuidadoras ou monitoras convivem diariamente com as crianças e adolescentes institucionalizadas e desempenham um papel fundamental na adaptação e no cuidado das mesmas. O papel do psicólogo é de grande relevância dentro de uma casa abrigo, podendo ser responsável pela avaliação da criança e sua família, apontando as mudanças necessárias para sua reintegração, preservando assim o vínculo familiar, além de oferecer treinamento e suporte à equipe técnica (Centro de Capacitação e Incentivo à Formação de Profissionais, Voluntários e Organizações que Desenvolvem Trabalho de Apoio à Convivência Familiar [CECIF], 2005).

Rev. Psicol Saúde e Debate. Dez., 2018:4(3):32-45. 
Considerando o estágio na prática e a literatura especializada, foi feita a opção por desenvolver um projeto de intervenção que estivesse voltado para a promoção e o fortalecimento da afetividade entre as crianças e os adolescentes abrigados através da técnica do brincar. A brincadeira é uma linguagem infantil que mantém um vínculo essencial que articula a imitação do real e do imaginário.

No ato de brincar, os sinais, os gestos, os objetos e os espaços possuem um significado além do óbvio. Ao brincar as crianças recriam e repensam os acontecimentos vivenciado por eles, a brincadeira favorece a autoestima das crianças, auxiliando-as na formação de sua personalidade saudável e a superar progressivamente suas aquisições de forma criativa (Santos, 2007).

Diante dessa realidade, o objetivo do presente trabalho, realizado na forma de relato de experiência, foi apresentar as aprendizagens obtidas durante o Estágio Básico II do 7ํㅜ período do curso de Psicologia da Faculdade Patos de Minas, elucidando suas etapas, capacitando e auxiliando o graduando de Psicologia a lidar com a realidade em uma casa de acolhimento de crianças e adolescentes.

\section{MÉTODO}

Este relato faz parte da produção resultante do Projeto de Pesquisa Relatos de Casos \& Relatos de Experiência: a prática desenvolvida no CEPPACE do DPGPSI/FPM. Submetido à apreciação ética do Comitê de Ética e Pesquisa (CEP) com Seres Humanos da Faculdade Patos de Minas, CAEE: 92972318.0.0000.8078, tendo como instituição proponente a Associação Educacional de Patos de Minas - AEPM mantenedora da Faculdade Patos de Minas, sob parecer de aprovação número: 2.758.999, de 06 de julho de 2018.

Primeiramente foram agendadas 6 (seis) visitas, nas quais foram feitas as observações que nortearam o desenvolvimento do projeto a ser executado. Em seguida, foi feito a entrega dos convites para as crianças participarem de uma tarde com atividades variadas. A entrega destes convites foi um momento muito afetuoso, as crianças demonstraram muita alegria e se mostraram bastante entusiasmadas e curiosas para participarem das atividades propostas. Foi utilizada a técnica do brincar enquanto atividade prazerosa e promotora de sociabilidade e para isso foram elaboradas diferentes brincadeiras e oficinas, tendo em vista atividades relevantes para o desenvolvimento infantil. A intervenção foi desenvolvida em um único dia, seguindo os seguintes passos:

Rev. Psicol Saúde e Debate. Dez., 2018:4(3):32-45. 
Tabela 1. Atividade Introdutória: Fazendo Arte

\section{ETAPA}

\section{ATIVIDADE}

\begin{tabular}{cc}
\hline Passo 1 & Reunir as crianças cantando e dançando. \\
\hline Passo 2 & Separar as crianças por idade, reforçando o convite. \\
\hline Passo 3 & $\begin{array}{c}\text { Levar os dois grupos para as quadras separadamente, onde os estagiários estarão } \\
\text { esperando as crianças. }\end{array}$ \\
\hline Passo 4 & Explicar às crianças como será executada cada oficina \\
\hline Passo 5 & Entregar o material para cada criança de acordo com a sua escolha \\
\hline Passo 6 & $\begin{array}{c}\text { Confecção de dois cartazes com os trabalhos realizados e uma exposição de obras } \\
\text { com massinhas de modelagem }\end{array}$ \\
\hline Passo 7 & Realização de pintura corporal \\
\hline Passo 8 & $\begin{array}{c}\text { Momento de reflexão a respeito do que as crianças acharam das oficinas e } \\
\text { perguntas sobre suas expectativas em relação ao futuro (qual profissão deseja seguir?) }\end{array}$ \\
\hline Passo 9 & Confraternização com lanche \\
\hline Passo 10 & Encerramento e agradecimento a todos da instituição com a entrega de um doce em \\
\hline
\end{tabular}

Fonte: Elaborado pelos autores (2018)

Tabela 2. Atividade Livre

\begin{tabular}{lll}
\hline & Massinha de modelar; \\
& - & Folha sulfite impressa com desenhos variados; \\
& L & Lápis de cor; \\
& - & Tinta guache; \\
Recurso & Pincel; \\
Material & Papel Kraft; \\
& Cola Branca; \\
& Palitos de Picolé; \\
& Copinho de Café; \\
& Livros variados. \\
& Desenvolver habilidades motoras; \\
& Ampliar a capacidade de expressão de diferentes formas; \\
& Promover boa interação entre os estagiários e as crianças; \\
\hline Objetivo & &
\end{tabular}

Rev. Psicol Saúde e Debate. Dez., 2018:4(3):32-45. 
demais.

Fonte: Elaborado pelos autores (2018)

Tabela 3. Mural

Interagir de maneira lúdica e divertida com as crianças e os

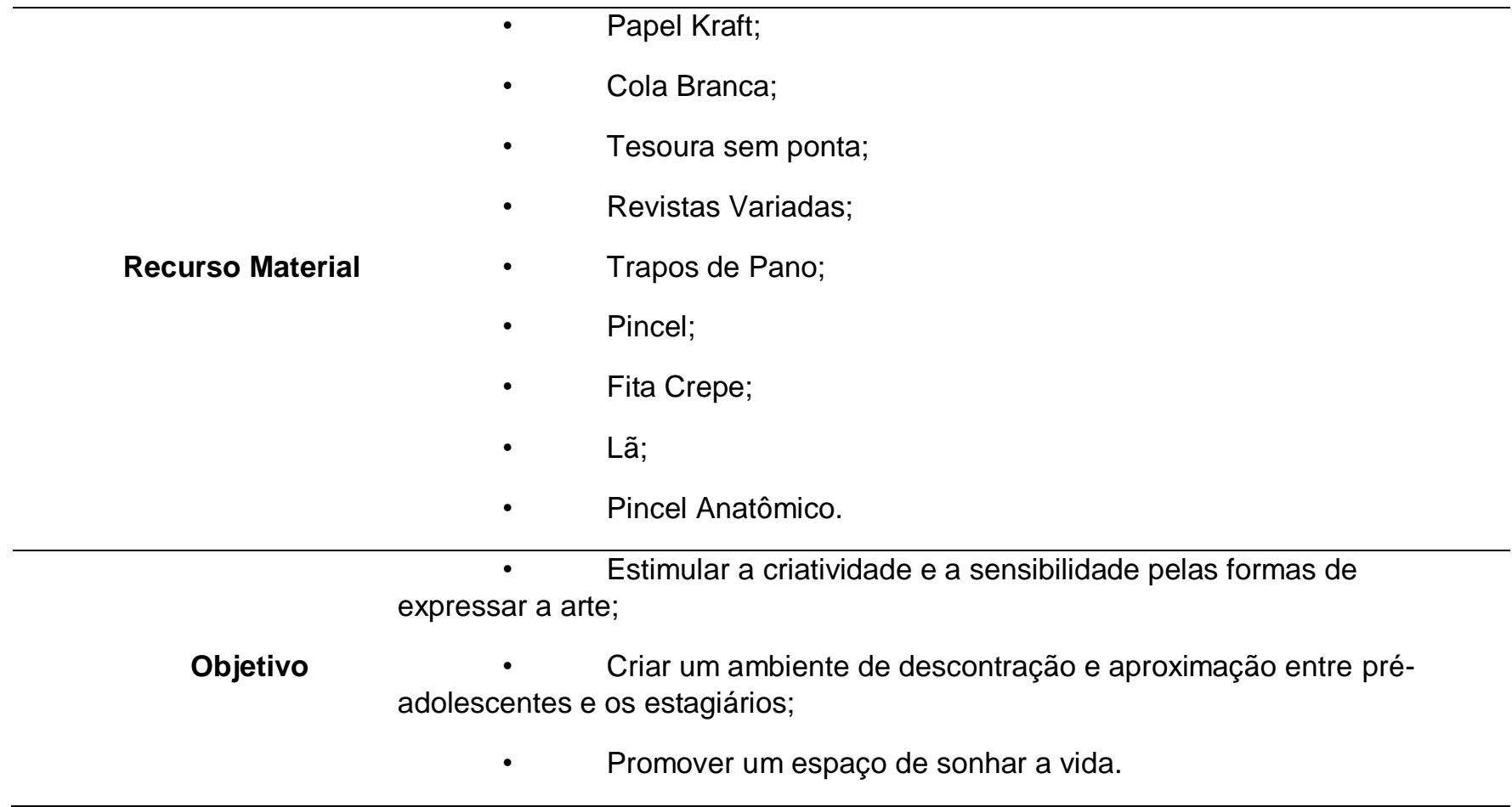

Fonte: Elaborado pelos autores (2018)

A implementação da intervenção foi previamente agendada, sendo no dia 06 de junho de 2017 das 13 horas às 15 horas. O projeto foi desenvolvido como previsto no cronograma e as crianças participaram ativamente das atividades propostas com bastante entusiasmo. Foi uma tarde de muitas brincadeiras e descontração para as crianças e estagiários, que não mediram esforços para o evento acontecer de forma a contribuir para satisfação e alegria dos institucionalizados

\section{RELATO DA EXPERIÊNCIA}

\subsection{AS OBSERVAÇÕES}

Rev. Psicol Saúde e Debate. Dez., 2018:4(3):32-45. 
O primeiro encontro com as crianças e demais funcionários foi agendado previamente, foi notada bastante ansiedade no momento de conhecer a instituição e as crianças, o que aconteceu logo após a chegada da psicóloga responsável pelo local.

O primeiro lugar apresentado foi uma sala de televisão com extensos bancos de alvenaria. Ali encontravam-se 2 (dois) meninos de aproximadamente 10 (dez) anos de idade assistindo TV. A psicóloga fez uma breve apresentação, eles acenaram ligeiramente sem interromper o que estavam assistindo. Logo adiante, em uma pequena sala, onde era a sala de estudos, havia outra criança em uma mesa fazendo suas atividades escolares de casa, fomos apresentados e ela esboçou apenas um pequeno sorriso e aproveitou a oportunidade para avisar que o computador estava estragado.

A psicóloga abriu uma porta de onde era um quarto com 3 (três) berços e havia uma criança dormindo em um deles. Na parte superior estavam os dormitórios das crianças, eram 3 (três) grandes quartos com várias camas. Na parte inferior foi visto o refeitório: uma sala ampla com 2 (duas) mesas grandes com cadeiras, em seguida foi apresentada a cozinha com um fogão industrial e a geladeira, que estava em uma pequena área de serviço fechada a chave. Foi explicado que muitas crianças têm restrição alimentar e somente assim era possível controlar a alimentação deles.

Do lado de fora, em uma área externa ampla e com telhado, estavam 2 (duas) cuidadoras sentadas em uma mesa alimentando 1 (um) bebê de aproximadamente 9 (nove) meses e 2 (dois) meninos de aproximadamente 4 (quatro) anos cada. Foi explicado para ele sobre o estágio, e então as crianças menores se mostraram receptivas e interessadas na presença dos estagiários e quiseram apresentar objetos, brinquedos e alguns livros, já as crianças maiores e os adolescentes se mostraram indiferentes. Havia também algumas crianças jogando bola na quadra, neste primeiro encontro tudo era novidade para todos.

No tempo proposto de 2 (duas) horas a visita foi encerrada e a próxima agendada. Este primeiro encontro desencadeou emoções e sentimentos de tristeza e impotência nos estagiários diante da situação das crianças carentes separadas de suas famílias e da fragilidade dos bebês sem a presença materna.

No segundo encontro, as crianças que se encontravam na instituição estavam em locais diversos da casa, alguns em suas atividades escolares, outros na sala de televisão e alguns na quadra coberta jogando bola. Dois pequenos brigavam por causa de brinquedos, os bebês eram gêmeos e estavam em seus carrinhos na área externa com uma cuidadora, que alimentava os dois ao mesmo tempo. Os estagiários observaram aquele momento e foi percebido que as 
cuidadoras se atentavam em dar atenção e carinho às crianças carentes que eram incapazes de entender sua situação.

Uma das crianças menores se aproximou rapidamente dos estagiários levando alguns brinquedos e em seguida uma outra criança apareceu chorando e dizendo que os brinquedos eram seus. O primeiro justificou dizendo que os brinquedos pertenciam a todos, depois de muito discutir, cada um pegou um brinquedo e foram brincar individualmente, mas logo esqueceram esses brinquedos jogados no chão e começaram novamente a discutir por um velho livro. Em seguida um deles pegou o livro, disse que queria ouvir uma história, como o livro não era de histórias, foi improvisada uma no momento, que foi muito apreciada pela criança.

O encontro terminou dentro do prazo previsto de 2 (duas) horas. Foi notado a tamanha carência afetiva das crianças. Diante disso, os estagiários pretendiam começar a executar um projeto que pudesse contribuir de alguma maneira com o bem-estar e alegria desses menores. Como citado em Cintra e Souza (2010), é notório repensar os cuidados na instituição, a realidade dos abrigados indica que seria necessário a construção de novas propostas que possam minimizar o abandono e o sofrimento das crianças.

No terceiro encontro, as crianças menores receberam os estagiários carinhosamente e estavam bem comunicativas, se mostrando bastante entusiasmadas com a presença da equipe, que já não era mais considerada uma ameaça. No relacionamento com os estagiários, percebíamos que algumas crianças eram mais receptivas à aproximação, ao carinho e ao diálogo, enquanto outras se mostravam gentis, mas preferiam manter seu espaço. Contudo, as brincadeiras e conversas surgiam sempre de forma espontânea e na maioria das vezes de forma individual.

Algumas crianças mais velhas ainda permaneciam indiferentes à presença dos estagiários e pareciam não se interessar em criar um laço social. De acordo com Aguiar, Carrero e Rondina (2007), uma das principais dificuldades encontradas nas crianças abrigadas era que elas se apresentavam agressivas ou apáticas, aparentando ter medo de tudo e de todos e alheias ao que acontecia ao seu redor. Algumas crianças chegavam ao abrigo em condições de total abandono, desnutridas, com marcas de agressões pelo corpo, marcas de queimaduras, falta de higiene, até mesmo agressivas.

A rotina da casa era aparentemente a mesma, muito choro e muitas disputas por brinquedos. Alguns bebês não queriam ficar no carrinho, mas as cuidadoras com várias atividades a fazer, sem opção, deixavam as crianças chorando, então muitas vezes os estagiários tentavam ajudar no cuidado com os bebês.

O texto Luto e Melancolia de Freud (2012) relata um estado de desamparo biológico seria gerador das primeiras experiências de angústia, o fator biológico estabelece as primeiras Rev. Psicol Saúde e Debate. Dez., 2018:4(3):32-45. 
situações de perigo e cria a necessidade de ser amado que acompanhará a criança durante o resto de sua vida.

Cada hora que passada com as crianças foi um aprendizado para os estagiários e muito importante para perceber e entender a carência afetiva das crianças, que foram obrigadas a deixar seus lares e viver em um abrigo sem suas famílias. Era evidente a presença do psicólogo naquele momento para ajudar a amenizar as consequências para o psiquismo daqueles pequenos defendendo a importância do olhar afetuoso.

Estar presente naquela casa para os estagiários desencadeava sentimentos profundos que mudavam a maneira de pensar, de valorizar a família, a educação e a importância dos pais no convívio com os filhos. Ao mesmo tempo, possibilitava sentir também angustia e impotência por não saber o que oferecer naquela situação diante das carências das crianças.

No quarto encontro o turno da visita foi alterado com a finalidade de conhecer todos os moradores da instituição. As visitas de observação estavam sendo realizadas pela manhã e algumas crianças frequentavam a escola neste horário. A mudança de horário foi cheia de surpresas para os estagiários que conheceram mais crianças, dentre eles 3 (três) irmãos, uma menina de aproximadamente 9 (nove) anos e 2 (dois) meninos pequenos com idade entre 2 (dois) e 4 (quatro) anos. A irmã mais velha estava sempre atenta aos irmãos menores, que brigavam com outras crianças enquanto ela tentava defender os irmãos, bastante indefesos. Naquele momento mesmo sendo uma criança, ela ocupava o papel de mãe, pai e cuidadora de seus irmãos.

O ambiente da casa de acolhimento era sempre agitado, com pequenas discussões, empurrões e muito choro entre as crianças. Em meio a tantas adversidades os estagiários podiam oferecer carinho, atenção e consolo, o que parecia muito pouco diante de tudo acontecia no abrigo.

Neste encontro, os bebês gêmeos estavam adoecidos, muito gripados e um choro incontrolável. A carência materna era notória naquele momento, pois a função materna é essencial para a organização psíquica do infante e sua constituição como sujeito. Pode-se dizer que é a partir da organização psicológica desenvolvida do relacionamento com a mãe ou com a sua cuidadora a criança conquista a capacidade de se relacionar com o resto do mundo dos objetos humanos (Coppolillo, 1990). Diante disso percebe-se a importância de se estabelecer uma relação de afeto, acolhimento e muito carinho com estas crianças.

As crianças maiores entre 9 (nove) e 14 (quatorze) anos ainda se mostravam indiferentes à presença dos estagiários. Mesmo após convida-los a estar juntos em alguma conversa ou alguma atividade que pudesse chamar a atenção, eles trocavam algumas palavras e logo partiam sem qualquer interesse em uma aproximação. Diferente das crianças menores, eles haviam Rev. Psicol Saúde e Debate. Dez., 2018:4(3):32-45. 
desistido de tentar aproximar e estabelecer vínculos afetivos? Estariam eles 'calejados' sabendo que os estagiários iriam embora? Para que se apegar a alguém que vai lhe deixar?

Com base na literatura especializada sobre o assunto é possível supor que o histórico de violência experimentado pelas crianças dificulta a formação de vínculo de confiança com o profissional de psicologia e cuidadores. Como citado em Aguiar et al. (2007), uma das principais dificuldades observadas ao chegarem no abrigo, foi a chegada das crianças em condições de total abandono, elas se apresentavam agressivas e apáticas, aparentando ter medo de tudo e de todos e alheias ao que estava acontecendo, evitando qualquer tipo de socialização com a equipe de acolhimento.

No quinto encontro, foi compartilhada a informação de que as crianças estavam se recuperando de um quadro viral que havia afetado $90 \%$ deles, incluindo até mesmo as cuidadoras e funcionárias, então os estagiários levaram frutas e sucos para os internos. Este encontro foi marcado como o mais difícil para os estagiários, até as crianças menores que se alegravam com a chegada da equipe estavam indispostas, algumas com febre e outras com diarreia. Neste dia não estavam disputando brinquedos e muito menos atenção, se mostravam apáticas e muitas vezes irritadas. A equipe chegou no momento em que uma cuidadora estava tentando alimentar os bebês gêmeos, eles estavam febris, com dificuldade para se alimentar e choravam mais que nos outros dias, além de não conseguir dormir.

Foi possível perceber de forma muito clara a falta da figura materna naquele momento difícil, em que deveriam ser consolados com um carinho de mãe. Neste dia a visita foi encerrada de forma difícil pelos estagiários, pois foi notado como era difícil para aquelas crianças doentes não ter a mãe naquele momento para cuidar e dar carinho.

No contexto da proteção da criança contra a violência e a amenização dos danos por ela causados, os profissionais da psicologia se ressaltam, tendo em vista seu papel protetivo e o potencial para auxiliar na amenização dos danos psicológicos causados as crianças e adolescentes vitimados (Silva \& Melo, 2017).

O estágio trouxe uma reflexão sobre o papel do psicólogo a ser desempenhado nas instituições de acolhimento e no preparo para o convívio com tais situações desafiadoras de forma coerente. Além disso, foi possível aprender também uma noção da dificuldade para o psicólogo estar exposto e absorver as angústias e ansiedades próprias de uma instituição de acolhimento de crianças retiradas de suas famílias.

\section{A INTERVENÇÃO}

Rev. Psicol Saúde e Debate. Dez., 2018:4(3):32-45. 


\subsection{O CONVITE}

O sexto encontro foi marcado para as $18 \mathrm{hrs}$, pois seria um horário em que todas as crianças estariam na instituição e era necessário encontrar com todas juntas para fazer o convite do projeto 'Fazendo Arte'. O convite tinha a intenção de mostrar que todas as crianças são importantes, por isso era individual, personalizado e criativo. As crianças ficaram bastante entusiasmadas ao receberem o convite no qual havia a seguinte proposta: estourar um balão, que possuía dentro uma mensagem que dizia que a presença de cada um deles era esperada no sábado para uma tarde cheia de surpresas.

A entrega dos convites foi um momento muito especial para a equipe de estagiários e para as crianças, que ficaram imensamente felizes com a proposta de uma tarde de descontração com atividades variadas para todos. O interesse era grande em saber quais eram as atividades e quando seria o encontro, então foi explicado que seriam atividades variadas para todas as faixas etárias. A alegria das crianças foi contagiante.

Os convites foram entregues e foi firmado o compromisso para o sábado a tarde. As crianças seguravam as pernas dos estagiários para não saírem e não queriam se despedir. Depois de vivenciar as dificuldades vividas por aquelas crianças no seu cotidiano, era gratificante para a equipe poder sentir naquele instante a gratidão, o entusiasmo e o carinho delas para um encontro especial.

Foi percebida a real necessidade de atividades com intuito de desenvolvimento socialafetivo nesse contexto do abrigo onde vivem crianças com diferentes dificuldades a serem enfrentadas. Foi muito importante notar como uma ação simples como um convite afetuoso e interessado despertou nas crianças sentimentos de entusiasmo e a oportunidade de serem notados. Já os estagiários, sentiram-se esperançosos com a possibilidade de oferecer uma tarde agradável que desse a essas crianças um momento de distração em que pudessem esquecer suas dificuldades e apenas serem crianças.

\subsection{EXECUÇÃO DO PROJETO}

Por meio das visitas realizadas na instituição de acolhimento foi observado inicialmente as diferenças de idade das crianças que lá se encontram, tendo elas a variação da primeira infância (de 0 aos 3 anos) ao final da segunda infância (a partir dos 3 anos até a préadolescência). Foi percebido em muitos momentos a dificuldade de relacionamento entre as crianças, o individualismo e até mesmo o retraimento, por não querer compartilhar e brincar em equipe. Algumas crianças eram mais receptivas à aproximação, ao carinho e ao diálogo, Rev. Psicol Saúde e Debate. Dez., 2018:4(3):32-45. 
enquanto outras eram gentis, mas preferiam manter seu espaço. Foi partindo daí que surgiu a ideia de um projeto que contribuísse com a interação positiva, orientada e a vivência harmoniosa dessas crianças, enquanto permanecessem institucionalizadas.

A brincadeira orientada tem sido vista por muitos autores como uma atividade relevante para o desenvolvimento infantil, uma vez que está bem presente no cotidiano da criança. Por meio da brincadeira a criança pode descobrir o mundo, vivenciá-lo, conhecer a si próprio e desenvolver seu potencial criativo. Na medida em que correm, pulam, brincam de casinha, de médico, de faz-de-conta, as crianças vão construindo relações com o ambiente que os cercam, com os objetos que os rodeiam e exploram o mundo.

Por meio da brincadeira eles também conseguem compreender melhor seus parceiros, compartilhar sentimentos positivos e negativos, bem como transmitir regras e valores de sua cultura. Dessa forma, é pertinente estar sempre resgatando o lúdico para compreender o desenvolvimento infantil nos abrigos, haja vista a criança ser intrinsecamente motivada a interagir com seus parceiros de idade, principalmente para brincar (Alves \& Sommerhalder, 2006).

\subsubsection{As oficinas}

A equipe de estagiárias foi dividida em três partes, ficando cada uma das partes responsáveis por uma oficina (duas) e uma pelo lanche.

a) Oficina livre: Para as crianças da primeira infância ( 0 a 3 anos) foi montada uma estrutura com algumas mesas com materiais como: lápis de cor, giz de cera, massinha de modelar, tinta guache, desenhos impressos para colorir ou pintar, palitos de picolé, pincéis (dentre outros materiais citados nas tabelas deste relato). Os materiais foram deixados à disposição das crianças, que seriam orientadas se necessário e sendo supervisionadas para que não se machucassem com materiais indevidos, objetivando a interação livre entre elas.

b) Oficina de colagem: Para as crianças pré-adolescentes, foram colocados sobre a mesa e sobre o tatame (chão coberto) materiais diversos como: papel kraft, cola branca, revistas variadas, pincel, tesoura sem ponta, lã e pincel atômico. Foi pedido que as crianças montassem de maneira 'criativamente livre' no espaço do papel Kraft tudo o que desejassem ou sonhassem para seu futuro e que finalizassem escrevendo uma palavra ou frase no cartaz. Dessa maneira, foi possível estimular a criatividade e a sensibilidade pelas formas de expressar a arte e criando um ambiente de descontração e aproximação entre os adolescentes e os estagiários. Foi um momento de reflexão com os jovens sobre seus anseios, desejos e em relação a qual profissão escolher. 
c) Encerramento: Após a execução das oficinas, foi formado um círculo e apresentado o trabalho realizado pelas crianças, destacando o esforço de cada um e seus atributos. Um espaço foi deixado em aberto para perguntas (caso houvesse) e após isso os materiais foram organizados com o auxílio das crianças. Foi agradecida a presença e participação de todos e logo após aconteceu o lanche de confraternização e encerramento. Foi uma tarde de muita descontração onde as crianças mostraram suas habilidades, criatividade e ainda interagiram descontraidamente com as estagiárias e os internos da instituição.

\section{CONSIDERAÇÕES FINAIS}

O presente relato de experiência contribui para graduandos de psicologia e demais interessados em elaborar, compreender e executar um projeto de Estágio Básico II em Psicologia. Possibilita vivenciar e lidar com as diferentes trajetórias possíveis da rotina de uma casa de acolhimento institucional na qual o psicólogo desempenha diferentes funções como técnico-administrativo, psicólogo clínico e, em alguns momentos, exerce a função de cuidador.

Para atuar no âmbito do acolhimento institucional pode-se concluir que o profissional deve digerir emocionalmente as adversidades encontradas de forma a poder estar junto com as crianças, família e cuidadores pensando alternativas de cuidados que possam amenizar a dor da separação dessas famílias (dentre outros sofrimentos).

As atividades de brincadeiras livres e oficinas desempenhadas na execução do projeto com as crianças e adolescentes foram um produto de um olhar clínico apurado que percebeu algumas das necessidades afetivas ali apresentadas. Se faz necessário ressaltar a importância desse tipo de atividade no cotidiano dessas instituições, foi uma experiência única e foi observado o quanto as crianças estavam felizes e descontraídas. Foi oferecido acima de tudo oportunidade de brincar em equipe, estreitar laços de amizade e companheirismo, proporcionando um momento em que as crianças foram apenas crianças.

Muito há o que se pensar sobre a atuação do profissional de Psicologia nesse tipo de instituição, principalmente no que se refere a posição que o mesmo ocupa. Acreditamos que o psicólogo deve-se manter no lugar de quem cuida do psiquismo e, portanto, responsável pela saúde mental das crianças recebidas. Assim, conclui-se que seu posicionamento técnico e teórico deve ser pautado na Clínica Ampliada, criando e desenvolvendo ações voltadas ao cuidado emocional dos acolhidos.

\section{REFERÊNCIAS}

Rev. Psicol Saúde e Debate. Dez., 2018:4(3):32-45. 
Aguiar, O. X., Carrero, M. L., \& Rondina, R. C. (2007). Casa abrigo: possibilidade de atuação para o psicólogo. Revista científica eletrônica de psicologia, 9(5), 1-7.

Alves, F. D. \& Sommerhalder, A. (2006). O Brincar: linguagem da infância, linguagem do infantil. Motriz, 12(2), 125-132.

Antoni, C., \& Koller, S. H. (2001). O psicólogo ecológico no contexto institucional: uma experiência com meninas vítimas de violência. Psicol. Ciênc. e Profissão, 21(1), 14-29.

Brasil. (1990). Estatuto da Criança e do Adolescente (Lei no 8069, de 13 de agosto de 1990). Brasília, DF: Presidência da Presidência.

Brasil. (2004). Resolução no 08 de 07 de maio de 2004 - Diretrizes Curriculares Nacionais para os cursos de graduação em Psicologia. Conselho Nacional de Educação/Câmara de Educação Superior. Brasília, DF: DOU.

Brasil. (2009). Lei 12.010 de 03 de agosto de 2009: dispõe sobre a adoção; altera as Leis no 8069, de 13 de julho de 1990 - Estatuto da Criança e do Adolescente, 8560, de 29 de dezembro de 1992; revoga dispositivos da Lei no 10.406, de 10 de janeiro de 2002 - Código Civil, e da Consolidação das Leis do Trabalho - CLT, aprovada pelo Decreto -Lei ํㅜ 5.452, de $1^{\circ}$ de maio de 1943; e dá outras providências. Brasília, DF: DOU.

Centro de Capacitação e Incentivo à Formação de Profissionais, Voluntários e Organizações que Desenvolvem Trabalho de Apoio à Convivência Familiar (Org.). (2005) 101 perguntas e respostas sobre reintegração familiar: o trabalho a partir dos sistemas de acolhimento institucional e familiar. São Paulo: Autor, 2005.

Cintra, A. L., \& Souza, M. (2010). Institucionalização de crianças: leituras sobre a produção da exclusão infantil, da instituição de acolhimento e da prática de atendimento. Revista mal estar e subjetividade, 10(3), pp. 809-833.

Coppolillo, H. (1990). Psicoterapia psicodinâmica de crianças. Porto Alegre, RS: Artes Médicas.

Freud, S. (2012). Luto e melancolia (1 ${ }^{\underline{a}}$ ed.). (M. Carone, Trad.) Rio de Janeiro, RJ: Imago.

Hoepfner, A. M. (2004). A Arte da Gestalt Terapia no Trabalho em Psicologia Social e Comunitaria. Revista de Gestalt Instituto Sedes Sapientiae, 13(n), 17-25.

Rotondaro, D. P. (2002). Os Desafios Constantes de uma Psicóloga no Abrigo. Ciencia e Profissão, 22(3), 8-13.

Santos, G. G. (2007). A importância do brincar na formação do sujeito. Revista científica multidisciplinar núcleo do conhecimento, 1(5), 41-56. 